Perspective

\title{
Green Prescriptions and Their Co-Benefits: Integrative Strategies for Public and Environmental Health
}

\author{
Jake M. Robinson ${ }^{1,2,3,4, *(D)}$ and Martin F. Breed 4,5 (D) \\ 1 Department of Landscape, University of Sheffield, Sheffield S10 2TN, UK \\ 2 inVIVO Planetary Health, of the Worldwide Universities Network (WUN), West New York, NJ 10704, USA \\ Improving Wellbeing through Urban Nature (IWUN), Sheffield S10 2TN, UK \\ 4 Healthy Urban Microbiome Initiative (HUMI), Adelaide, SA 5005, Australia; martin.breed@adelaide.edu.au \\ 5 School of Biological Sciences and the Environment Institute, the University of Adelaide, Adelaide, SA 5005, \\ Australia \\ * Correspondence: jmrobinson3@sheffield.ac.uk
}

Received: 10 December 2018; Accepted: 11 January 2019; Published: 17 January 2019

\begin{abstract}
There is a growing recognition of the links between the increasing prevalence of noncommunicable diseases, environmental concerns including biodiversity loss and ecosystem degradation, and socioecological issues such as ecological (in)justice. This has encouraged a number of recent calls for the development of integrative approaches aimed at addressing these issues-also known as nature-based solutions. An example of an emerging nature-based solution is a 'green prescription', broadly defined as a nature-based health intervention. Green prescriptions are typically designed for patients with a defined need and they have the potential to supplement orthodox medical treatments, particularly those aimed at addressing noncommunicable diseases. It is also thought that green prescriptions could bring about significant environmental, economic, and social co-benefits. However, researchers have recently expressed concerns over taking the 'dose of nature' approach, in that it may be too reductionistic for the complex social settings in which it is provided. Here we frame a holistic philosophical perspective and discuss green prescribing logic, types, mechanisms and fundamental remaining questions and challenges. We place a significant emphasis on the potential co-benefits of green prescriptions, and the importance of taking a planetary health approach. More research is needed to determine how this potential can be realised, and to further understand the complexities of the nature-human health relationship. However, with additional research and support, there is huge potential for green prescriptions to contribute to both reactive (health care) and proactive (health promoting) public health solutions whilst enhancing the natural environment.
\end{abstract}

Keywords: green prescriptions; planetary health; urban nature; biodiversity; microbiome; mental health; nature connectedness; greenspace; noncommunicable diseases; nature-based interventions

\section{Introduction, Issues and Philosophical Perspective}

There have been many recent improvements to public health across the planet. Notable examples of these include significant reductions in cases of measles, mumps and rubella (MMR) as a result of widespread immunisation programmes in the mid-late 20th century [1,2], and an increase in breast cancer survival rates following successful upstream mammography screening initiatives $[3,4]$. However, with such an abundant and ever-increasing global population, deeply intertwined with social and cultural complexities (preventing equity in resource distribution and the associated health benefits), there is still a significant amount of work to be done to improve human health and wellbeing. 
Environmental health issues such as biodiversity loss and ecosystem degradation may at first appear to develop independently to those in public health-however, they are often deeply connected [5,6]. There is growing recognition and understanding of these links, particularly between the increasing prevalence of noncommunicable human diseases, environmental concerns, and socioecological issues such as ecological (in)justice. This has encouraged recent calls for the development of integrative approaches that aim to address these issues holistically-also known as nature-based solutions ( $\mathrm{NbS}$ ) $[7,8]$. An example of an emerging $\mathrm{NbS}$ is green prescribing, broadly defined as a nature-based health intervention. Green prescriptions are typically designed for patients with a defined need, and they have the potential to supplement orthodox medical treatments, particularly those aimed at addressing noncommunicable diseases [9]. It is also thought that green prescriptions have the potential to bring about significant environmental, economic, and social co-benefits $[10,11]$.

Our paper aims to explore green prescriptions and their co-benefits in greater detail. We provide an overview of two of the key issues that green prescriptions could potentially help to address-a need for public health innovation, and new strategies that support ecosystem resilience and biodiversity conservation. This is followed by a planetary health-driven philosophical framework that underpins this 'integrative strategy' approach. We then discuss green prescribing logic, types and mechanisms, which are followed by a discussion of their potential co-benefits. Finally, we highlight some of the fundamental remaining questions and concerns regarding their effectiveness.

\subsection{Issue 1: A Need for Public Health Innovation}

In a number of studies investigating the social determinants of public health, attention has been drawn to the uncomfortable reality of the pressing need for public health and socioeconomic innovation [12-14]. These studies highlight significant health inequalities in many countries. Other studies arrive at equally striking conclusions regarding the risk factors for chronic diseases and the associated impacts upon general health, mortality and the economy. For example, Scarborough et al. (2011) estimated that in July 2006, chronic diseases related to poor dietary habits, physical inactivity and obesity cost the UK National Health Service (NHS) $£ 11.8$ billion [15]. A similar story unfolds for mental health and wellbeing, with an annual expenditure of up to $£ 13$ billion allocated to the management of mental health conditions in England alone [16].

Despite significant improvements in certain areas of public health, recent estimates suggest that $61 \%$ of adults in England are considered to be overweight or obese [17] - both of which are risk factors for noncommunicable diseases (NCDs) such as diabetes and cardiovascular-related illnesses [18,19]. Moreover, around one in four people experience mental health issues in the UK each year [20,21]. These conditions are diverse, often co-morbid with other NCDs [22,23], and they are thought to be responsible for 38 million annual deaths across the planet [24,25].

These findings highlight the need to develop innovative strategies to:

- Improve public health and wellbeing;

- Close the health inequality gap; and,

- Alleviate the financial burden currently facing health services and the wider economy

\subsection{Issue 2: Biodiversity Conservation and Ecosystem Resilience}

The natural environment provides a significant amount of provisioning, supportive, regulatory and cultural benefits to humans, and the processes and features that generate these benefits are now commonly referred to as 'ecosystem services'. It cannot be overstated that the existence of humanity, along with societal health and wellbeing, is highly dependent upon these so-called 'services', and the diverse array of organisms they support $[26,27]$. However, our decisions and actions are often detrimental to the environment, and the urban lifestyle is one of the fundamental anthropogenic drivers of biotic restructuring, often to the detriment of biological diversity and ecosystem functionality [28]. 
For example, two issues associated with biodiversity loss are natural resource exploitation and pollution. The former is a key input in the process of urban development, often resulting in habitat loss and a subsequent reduction in genetic and species diversity [29,30]; whereas pollution is a key output and 'by-product' of urbanisation, and it can lead to widespread negative impacts on the global biological systems that support biodiversity [31].

There have been recent calls to take an integrative approach towards addressing challenges associated with ecosystem resilience and human health and wellbeing (Figure 1). For example, Raymond et al. (2017) put forward a framework to promote the co-benefits (for environmental and public health) of nature-based solutions [7]. Furthermore, the field of planetary health also focuses strongly on the simultaneous management of human and environmental health [8].

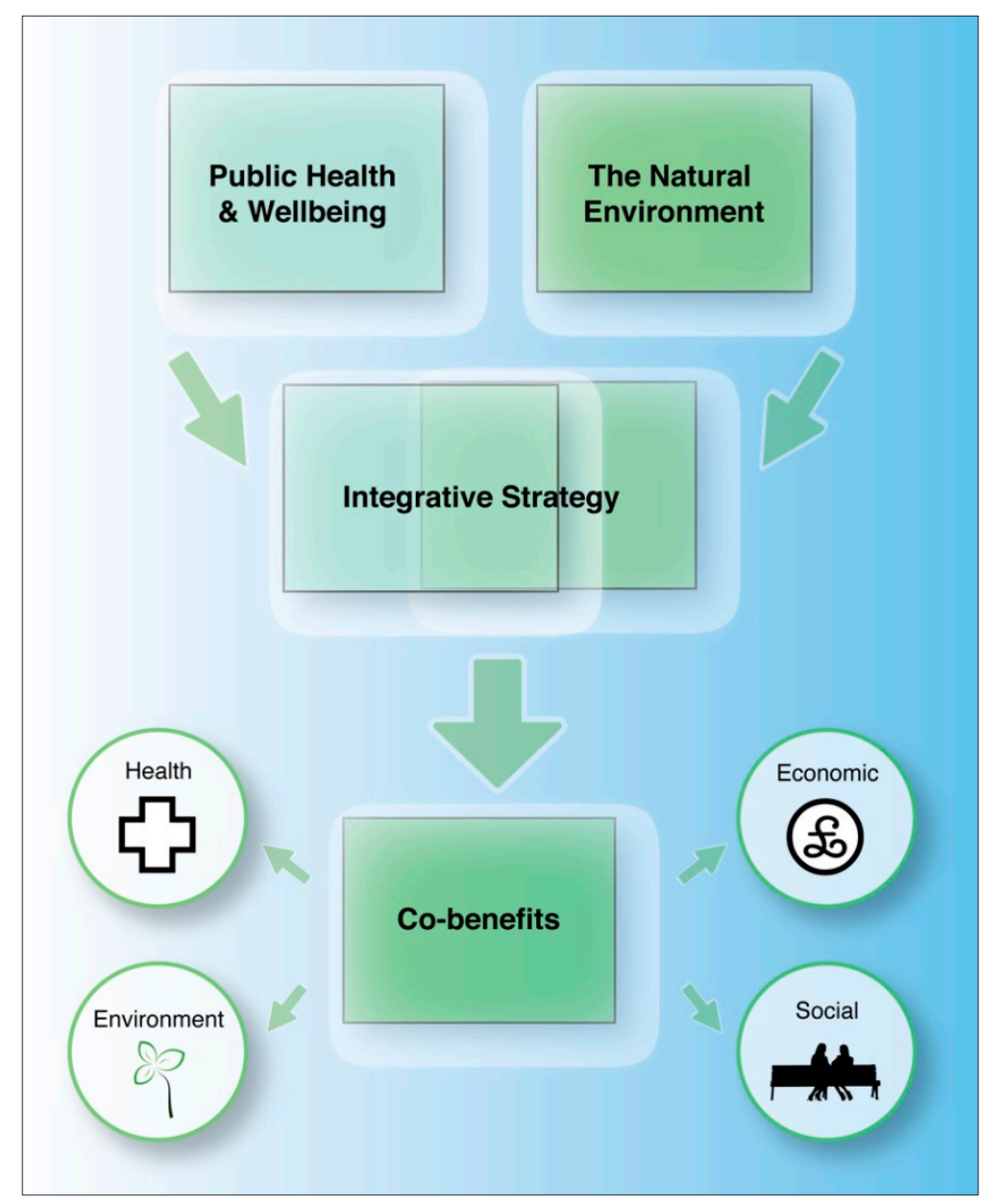

Figure 1. A call for integrative strategies that provide co-benefits for humans and nature (created by the authors).

\subsection{Planetary Health, Biophilosophy and the Symbiocene}

Issues surrounding public health-particularly noncommunicable diseases-and the growing threats to biodiversity and ecosystem resilience, can be viewed from a single overarching philosophical perspective, that is, from a planetary health perspective. Planetary health is an increasingly popular term that is used to describe the coupling nature of human and environmental health [32]. The concept was born out of the view that both of these growing issues are inextricably linked. For example, anthropogenic habitat alteration increases the risk of infectious diseases across the planet, and pollution increases the risk of cardiovascular diseases and cancer [33]; there are also strong relationships between planetary health and the quality of human nutrition, as well as displacement, conflict and mental health [33-35]. 
From an anthropocentric perspective, there are social, biological and psychological determinants of public health, and each domain can influence the other in a complex bio-eco-psycho-social network [36]. This phenomenon, along with the notion that all realms of life-both seen and unseen-are interconnected [37], is central to the philosophical foundations of this narrative. This philosophy lends itself to emerging calls for a newly recognised epoch, as voiced by several researchers and eco-philosophers [37,38]. These calls refer to an epoch dominated by mutually-advantageous relationships between humans and the environment, and not simply a unidirectional and exploitative relationship, as often characterised by the current 'anthropocene'. This proposed epoch has been labelled the 'symbiocene' [39], based upon aspirations for a move towards a more symbiotic, holistic and ecological approach to living. The symbiocene also includes a drive towards a healthcare model dominated by holistic medical and social practices [37]. However, epochs aside, to contribute to a value system characterised by a human-nature relationship with mutually-beneficial health outcomes, a philosophical approach similar to the 'biophilosophy' popularised by Salk appears to be a worthy starting point [40]. This approach requires a "coalition of thought from biologists, philosophers and humanists" [37], and has parallels with the recent interests in transdisciplinary research and the calls for integrative models, which include considerations for both biodiversity and healthcare (reactive) and health promotion (proactive) [41,42].

Also central to this narrative is the perceived growing 'disconnect' between human beings and natural environments [43]. Public health and social issues attributed to this disconnect manifest in various forms, including social stress and reduced psychological wellbeing [44,45]. Potential pathways leading to this disconnect include reduced exposure to natural environments, green space access issues, reduced environmental awareness and time spent in nature [46,47]. Furthermore, immunodeficiency disorders such as asthma and inflammatory bowel disease (IBD) are on the rise [48]. This has been partially attributed to reduced exposure to immunoregulatory microorganisms and other health-inducing biological compounds [49-52]. Obesity has also increased, resulting in part, from lower levels of outdoor-based physical activity and an increasing intake of ultra-processed foods [53,54].

Many ecological issues associated with the human-nature disconnect are multidimensional and include habitat destruction, pollution, biodiversity loss and human-wildlife conflict $[43,55]$. This disconnect likely diminishes pro-environmental behaviours and a general sense of environmental stewardship [55]. This may further exacerbate the pressures exerted on the environment, and subsequently exacerbate the human health issues, potentially setting a negative feedback loop in motion. Integrative strategies that exploit the reverse positive nature of the aforementioned feedback loop have huge potential. Green prescribing (Box 1) is one example of an integrative strategy that aims to support the nature-human relationship, and this will now be discussed in greater detail.

Box 1. A definition of a green prescription.

\section{Green Prescription:}

A prescription for a monitorable activity that involves spending time in natural environments for the benefit of human health and wellbeing.

\section{Green Prescriptions: An Integrative Approach}

It is perhaps important to note here that although the use (or at least the popularisation) of the term 'green prescription' has been a recent occurrence, the fundamental principles of nature-based therapies have been applied for centuries. For example, the Romans (influenced by the Greeks) constructed spa baths at thermal springs to enhance health and wellbeing [56]. Furthermore, to treat the symptoms of disease in the times of Hippocrates (460-370 BC) a "change of habits and environment was advised, which included bathing, perspiration, walking, and massages" [57] (p. 1). In Germany a similar practice called the Kur (cure or treatment) was also influenced by the Roman practice of therapeutic bathing, and became mainstream by the 1700s [58]. The Kur is now "part of a complex system of rehabilitation medicine utilizing medical bathing and environmental stimuli" [58] 
(p. 1). Recent evidence (including the use of cortisol as a biomarker) points to the use of spas/Kur as an effective intervention for managing stress-related disorders [59]. These treatments have also been associated with improvements in a number of conditions, from rheumatic and musculoskeletal diseases, to circulatory and nervous disorders [59].

A green prescription (in its contemporary form), also known as a nature-based health intervention, is an emerging, innovative strategy that is designed to improve physical and mental health and wellbeing through exposure to, and often multisensorial interaction with natural environments [9]. A regular walk through a green space, systematic participation in gardening (horticultural therapy), and/or the undertaking of biodiversity conservation activities, such as habitat creation and restoration, are all potential examples of green prescribing activities $[9,60]$. They can be viewed as a monitorable activity that involves spending time in natural environments for the benefits of health and wellbeing.

Green prescriptions are typically designed for patients with a defined need, and they have the potential to supplement orthodox medical treatments, particularly those that are aimed at addressing noncommunicable diseases and mental health issues [9]. Furthermore, it could be argued that green prescriptions could provide a reactive (health care) and a proactive (health promoting) solution to public health issues. Indeed, this dual approach could potentially materialize through contributions to improving the health of patients whilst promoting a healthy lifestyle and supporting the development and maintenance of health-promoting infrastructure.

The term 'green prescription' or 'GRx' was first coined by health professionals in New Zealand in the late 1990s to underscore a range of physical and dietary activities that aim to enhance the health and wellbeing of patients, and reduce NCDs such as Type-2 diabetes [61]. In this initiative, GPs provide patients with diet plans and strategic physical activities such as 'progressively increasing' steps, monitored with pedometers and follow-up telephone counselling [62]. The term has since been broadened to include nature-derived activities (e.g., horticulture, nature walks, biodiversity conservation) as part of a holistic and integrative approach aimed at addressing NCDs, mental health issues and social isolation.

It is acknowledged that the foundations of green prescribing often require the interactions of three main phenomena-natural environments, a social context and meaningful activities [9]. However, there is still a significant amount of research to be undertaken to answer a number of fundamental questions (Figure 2), such as what kinds of nature-based interventions (or elements of these) work best for whom, where and when?

Jepson, Robertson and Cameron (2010) [60] and Bragg and Leck (2017) [9] highlight the range of potential activities that may constitute a green prescription, and these include:

- therapeutic horticulture;

- biodiversity conservation;

- care farming (the use of farming practices for health, socialising and education);

- green exercise (e.g. nature walks, biking, climbing);

- $\quad$ wilderness arts and crafts

Many of the activities are suitable for a diverse range of users. Taking biodiversity conservation-based green prescriptions as an example, the associated tasks (often group-focused) are typically aimed at restoring, conserving and enhancing the diversity of flora and fauna. Whilst it is recognised that biodiversity conservation activities are not suitable for everybody, due to ability, interest and willingness (e.g., there may be several physical, mental, social, and/or access issues to take into consideration), based on the authors' experience of attending a wide range of conservation groups, the events tend to be highly sociable and attended by a diverse cohort. Furthermore, whilst acknowledging that this may differ between groups, no apparent pressure to participate in the more physical aspects of the activities was witnessed in the groups attended by the authors. Conservation activities are considered to be highly flexible in type and timescale, providing a range of benefits to people with 
very different abilities and backgrounds [11]. As with gardening equipment [63], conservation tools and infrastructure can also be adapted for people with disabilities.

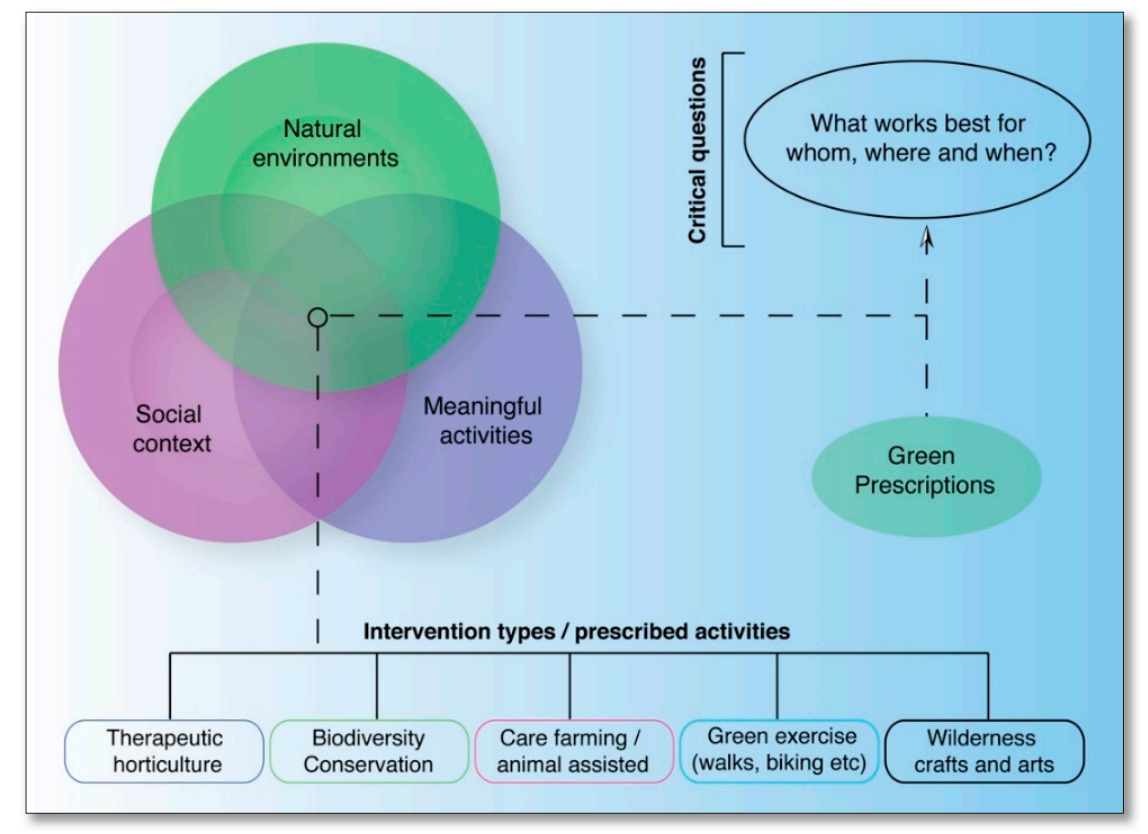

Figure 2. The interaction of the social context, natural environments and meaningful activities, and the potential types of nature-based interventions (created by the authors, partially adapted from [9]).

\section{Green Prescriptions: Potential Co-Benefits}

Hitherto, variations of green prescribing have been shown to generate health, social and financial gains, but only in a limited number of studies with small sample sizes and an absence of robust control measures $[10,64]$ - hence the emphasis on 'potential' co-benefits. However, a large number of potential co-benefits spanning areas of health, socioeconomics, and the environment have been identified by the authors (Figure 3). Mounting evidence from a wide range of studies investigating the relationship between nature and human health supports this—and in particular-the environmental benefits [10,65-67].

By developing strategic nature-based activities, there is an important opportunity to help address public and environmental health issues - that is, through the application of a well-defined co-beneficial strategy. An example where this could be realised is the Healthy Urban Microbiome Initiative (HUMI; www.humi.site) - a multidisciplinary initiative that was recently supported by the United Nations Secretariat for the Convention on Biological Diversity (CBD; https: / /www.cbd.int/health/ cop14/default.shtml). This initiative aims to understand and recreate the immune-boosting power of high quality, biodiverse green spaces in our cities to maximise population health benefits, bringing significant savings to health budgets while delivering gains for biodiversity [68]. Although more evidence of the mechanisms linking nature to health is needed, improving and maintaining green spaces in urban areas, particularly with high levels of biodiversity, could potentially lead to important health and environmental benefits. Enhancing the diversity of the human microbiome by encouraging interactions with natural environments and their microbial inhabitants (microbiome rewilding) is one such potential route [69]. Building on this theory, microbiome-inspired green infrastructure (MIGI) has recently been proposed as a collective term for the design and management of innovative living urban features that could potentially facilitate the process of microbiome rewilding in towns and cities across the planet $[50,51]$. 


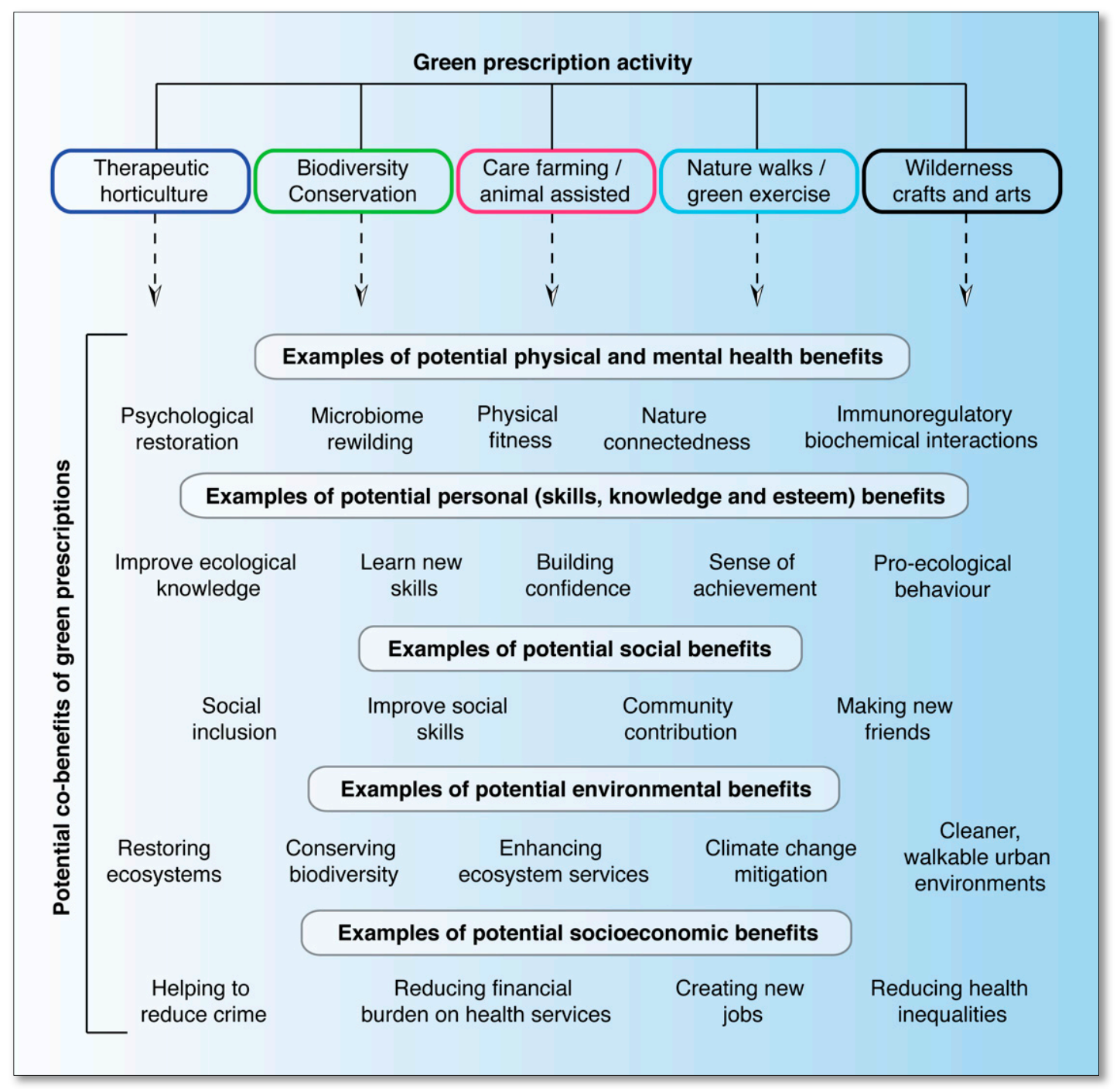

Figure 3. Potential green prescribing activities and co-benefits (created by the authors).

Green prescriptions potentially fit into this by providing an important social interface-a systematic process to enhance one's connection with biodiverse urban green spaces, which could be designed and monitored to suit the individual needs of the patients. As mentioned, biodiversity conservation volunteering is an activity that is associated with green prescriptions; therefore, the enhancement of green spaces and biodiversity across urban areas could be incorporated into a green prescribing strategy itself. Patients could contribute towards the enhancement and maintenance of biodiverse urban green spaces and MIGI, whilst improving their own health as a result of their participation.

In addition to physical and practical aspects (such as enhancing ecosystem services), gaining ecological knowledge, social confidence and communication skills are all potential co-benefits associated with nature-based interventions. Enhanced pro-ecological behaviours and environmental stewardship are some of the key potential co-benefits that could conceivably generate positive cascading impacts on the natural environment by influencing lifestyle decisions and positive changes that benefit nature. For example, these changes could include deciding to recycle, reducing the consumption of unsustainable products, and simply being more mindful of the wider biotic community.

However, although the potential co-benefits of green prescriptions are promising, there is still a need for further rigorous and evaluative research and interventions to confirm this, and to understand the dynamic complexity of the way in which individuals experience the natural world. 
As mentioned earlier, green prescriptions also have a potential financial co-benefit associated with them. Bloomfield (2017) pointed out that Mind's 'Ecominds' (a nature-based intervention programme) [70], reported savings per participant of $£ 7082$ via reduced costs to the NHS [10] (p. 83). This further corroborates studies that report significant financial gains in non-nature-based social prescribing [71,72].

It could be argued that green prescribing is founded on holistic principles (as with social prescribing models), and so it is also important to recognise that in addition to the proposed nature-derived pathways to health, green prescribing activities are often considered 'social events', which could potentially facilitate other indirect health-inducing benefits that have a social and community focus. This, in itself is another potential co-benefit.

\section{Challenges and Remaining Fundamental Questions}

There are copious studies promoting the potential benefits of nature-based health interventions $[73,74]$ and the evidence-base supporting the broader concept in terms of the nature-health relationship is growing increasingly stronger. However, there are limited empirical studies that scrutinise the functionality and sustainability of green prescribing schemes in practice. This is a key knowledge gap that warrants further in-depth investigation, preferably based on longitudinal study designs with robust evaluation frameworks.

One study conducted recently in Cornwall, UK [10] adopted different nature-based interventions. The different interventions included conservation activities, nature-walking and meditation. The interventions were carried out in areas defined as 'highly biodiverse'; however, the methods for determining this were not defined, and the habitats in which the interventions took place differed and included woodland and coastal habitats, which could have affected the results. For example, the various biotic and abiotic features of a woodland may (or may not) elicit different psychological, microbial and biochemical-based health-inducing mechanisms and effect sizes when compared to coastal habitats.

In terms of practical challenges associated with green prescriptions, Bloomfield highlighted an important point-that it will be imperative for coordinators of green prescribing schemes to speak two disciplinary 'languages': the language of healthcare, and the language of ecology. The author suggested that unless these two languages are acknowledged, coordinators may focus on gains for their respective disciplines, which could potentially devalue the important co-benefits.

Numerous researchers from New Zealand have evaluated the views of general practitioners (GPs) in relation to green prescribing $[61,75,76]$. Although these studies focus on the non-nature-based form of green prescribing (physical activity and diet), they do provide some interesting insights into unorthodox prescriptions, and the constraints and barriers associated with early implementation. For example, one study found that GPs were generally very receptive to the concept of green prescribing [75]. Another study assessed GP views following a green prescribing programme [76]. The authors identified several implementation-related constraints, namely, lack of time, perceived loss of revenue and the simplistic perception of green prescribing. However, these constraints, the authors suggested, were subsequently assisted in the wide-spread development of green prescriptions in New Zealand.

It could be argued that another key challenge facing the application of green prescribing is the way in which we currently think about public health-both in research and practice. This has recently been highlighted in a publication on biodiversity and urban healthcare initiatives, where the authors argue that we need more "place-based, preventative, wellness-focused healthcare systems that interact with urban planners, environmental managers and politicians to promote healthy urban designs and living" [68] (p. 5). There is no doubt that forming multi-stakeholder collaborations and taking integrative approaches (such as green prescriptions) to public and environmental health will be challenging, but they are challenges that are worth rising to, as the coupling issues of noncommunicable diseases and environmental degradation increase. 
Although green prescriptions have the potential to enhance human and environmental health, important questions are now being asked in terms of what works best for whom, where and when [77]. Answering these questions is critical if we are to gain the level of understanding that is needed to develop effective nature-based interventions that can justify the reallocation of limited resources. Rigorous evaluations are needed to identify appropriate interventions, and to understand the mechanisms and the contexts in which they are effective. There have been recent calls to take a more critical view of the 'dose of nature' approach, and to include a focus on social practices to cater for the complexities of how individuals experience and interpret nature [78]. This exemplifies the importance of diversity and holism in our approaches to public and planetary health.

\section{Future Studies}

It would be prudent for researchers to continue conducting natural experiments to assess the health and social impacts of green prescriptions, and in particular-to grasp research opportunities where green prescriptions are already (or are in the process of being) implemented. For this approach to be effective, systems must be developed to maximise intervention uptake (and engage those who will benefit the most), minimise 'drop out' rates, and ensure that the green prescribing in practice is both sustainable and consistent [79]. Furthermore, understanding who is currently prescribing nature-based interventions, and gaining insights into how they are funded, as well as what infrastructure/resources are needed, will play an important role in establishing productive collaborations between researchers and practitioners. By working closely with green prescription providers (e.g., environmental conservation charities) and prescribers (e.g., general practitioners), researchers have the opportunity to not only apply existing and to acquire new knowledge of the processes that influence exposure and effect, but importantly, to shape the intervention approach. This will be vital when it comes to gathering the appropriate evidence to inform the choice of intervention, and to maximise their potential co-benefits (e.g., health, environmental, social and economic).

Natural experiments are particularly important for population-based and epidemiological studies. However, studies with a clinical-style design, such as randomized control trials (RCT) will also be important for gaining a greater mechanistic understanding of the factors involved with health gains from green prescriptions. However, RCTs present a distinct set of challenges in natural environments, and they comprise less than $1 \%$ of published research in the field of environmental health [80]. As with any health-centric study, there are many potential confounding factors to consider (e.g., genetics, general health, diet, physical exercise, pets, age, and social contact), and the challenges are compounded by the complexity of the natural environment. However, with appropriate control measures and thorough consideration for these factors, RCTs are most certainly feasible.

Additional research should also be carried out to evaluate the potential economic impact of green prescribing on general medical practice. This will undoubtedly influence the sustainability of the interventions, and researchers may ask questions such as:

- Can green prescriptions save medical practices money and other resources?

- If so, which type of intervention is most effective?

- Does this vary between geographic regions or between areas with different socioeconomic statuses?

- Which patients will benefit the most from green prescriptions?

It will also be vital to gain a greater understanding of the downstream social and environmental impacts of green prescriptions. To investigate these factors, studies will likely benefit from longitudinal and mixed method designs. This further highlights the importance of establishing systems and collaborations that focus on the sustainability of nature-based (and other social) interventions. 


\section{Conclusions}

Green prescriptions have the potential to contribute towards improving human health and wellbeing. As an integrative strategy, green prescriptions also have a wide range of potential co-benefits. These include environmental benefits that are generated through the involvement of patients in activities that are aimed at enhancing biodiversity and by influencing the allocation of resources to maintain green infrastructure. The concept of green prescribing could also add an important dimension to the recent calls to rewild the microbiome by establishing microbiome-inspired green infrastructure (MIGI) in towns and cities-in that it could provide an interface that helps to facilitate health-inducing interactions with biodiverse environments.

Enhancements in pro-ecological behaviours and environmental stewardship could result from participating in nature-based interventions, and this could have important longer-term positive impacts on the environment. There is also evidence to suggest that nature-based interventions can generate a range of important social and financial benefits.

However, more research is needed-particularly longitudinal studies and evaluations of interventions-in order to fully understand the mechanisms behind the interventions, and the contexts in which they are most effective. The shift in thinking towards embracing a mutually advantageous relationship with nature and a move towards place-based health interventions will be challenging, but they are challenges worth rising to in the face of increasing noncommunicable diseases and environmental degradation. The importance of taking a holistic and diverse approach to enhance public and planetary health cannot be overstated. With further research, green prescriptions could make an important contribution to this approach, whilst providing reactive (health care) and proactive (health promoting) solutions to public health.

Author Contributions: Conceptualization, J.M.R.; methodology, J.M.R.; investigation, J.M.R. and M.F.B.; writing-original draft preparation, J.M.R. and M.F.B.; writing-review and editing, J.M.R. and M.F.B.; visualization, J.M.R.

Funding: J.M.R. is undertaking a PhD, funded by the Economic and Social Research Council (ESRC). M.F.B. is supported by the Australian Research Council and Australian Smart Cities Consortium.

Acknowledgments: Some of the work in this article was adapted from J.M.R.'s Masters in Social Research Thesis: A Dose of Nature: an interdisciplinary study of green prescriptions and the environment-microbiome-health axis. 2018, University of Sheffield.

Conflicts of Interest: The authors declare no conflict of interest.

\section{References}

1. Peltola, H.; Heinonen, O.P.; Valle, M.; Paunio, M.; Virtanen, M.; Karanko, V.; Cantell, K. The elimination of indigenous measles, mumps, and rubella from Finland by a 12-year, two-dose vaccination program. New Engl. J. Med. 1994, 331, 1397-1402. [CrossRef] [PubMed]

2. Vyse, A.J.; Gay, N.J.; White, J.M.; Ramsay, M.E.; Brown, D.W.; Cohen, B.J.; Hesketh, L.M.; Morgan-Capner, P.; Miller, E. Evolution of surveillance of measles, mumps, and rubella in England and Wales: Providing the platform for evidence-based vaccination policy. Epidemiol. Rev. 2002, 24, 125-136. [CrossRef] [PubMed]

3. Tabar, L.; Yen, M.F.; Vitak, B.; Chen, H.H.; Smith, R.A.; Duffy, S.W. Mammography service screening and mortality in breast cancer patients: 20-year follow-up before and after introduction of screening. Lancet 2003, 361, 1405-1410. [CrossRef]

4. Park, J.H.; Anderson, W.F.; Gail, M.H. Improvements in US breast cancer survival and proportion explained by tumor size and estrogen-receptor status. J. Clin. Oncol. 2015, 33, 2870-2876. [CrossRef] [PubMed]

5. Haahtela, T.; Holgate, S.; Pawankar, R.; Akdis, C.A.; Benjaponpitak, S.; Caraballo, L.; Demain, J.; Portnoy, J.; von Hertzen, L. The biodiversity hypothesis and allergic disease: World allergy organization position statement. World Allergy Organ. J. 2013, 6, 3. [CrossRef]

6. Von Hertzen, L.; Beutler, B.; Bienenstock, J.; Blaser, M.; Cani, P.D.; Eriksson, J.; Färkkilä, M.; Haahtela, T.; Hanski, I.; Jenmalm, M.C.; et al. Helsinki alert of biodiversity and health. Ann. Med. 2015, 47, $218-225$. [CrossRef] 
7. Raymond, C.M.; Frantzeskaki, N.; Kabisch, N.; Berry, P.; Breil, M.; Nita, M.R.; Geneletti, D.; Calfapietra, C. A framework for assessing and implementing the co-benefits of nature-based solutions in urban areas. Environ. Sci. Policy 2017, 77, 15-24. [CrossRef]

8. Ostfeld, R.S. Biodiversity loss and the ecology of infectious disease. Lancet Planet. Health 2017, 1, e2-e3. [CrossRef]

9. Bragg, R.; Leck, C. Good Practice in Social Prescribing for Mental Health: The Role of Nature-Based Interventions; Natural England Commissioned Reports; 2017. Available online: http://publications. naturalengland.org.uk/publication/5134438692814848 (accessed on 15 January 2019).

10. Bloomfield, D. What makes nature-based interventions for mental health successful? BJPsych Int. 2017, 14, 82-85. [CrossRef]

11. O'Brien, L.; Townsend, M.; Ebden, M. 'Doing something positive': Volunteers' experiences of the well-being benefits derived from practical conservation activities in nature. VOLUNTAS Int. J. Volunt. Nonprofit Organ. 2010, 21, 525-545. [CrossRef]

12. World Health Organisation. Commission on Social Determinants of Health. Closing the Gap in a Generation: Health Equity through Action on the Social Determinants of Health: Final Report of the Commission on Social Determinants of Health. 2008. Available online: http:/ /apps.who.int/iris/bitstream/handle/10665/ 43943/9789241563703_eng.pdf;jsessionid=8AD4D28DF8105162B09759F36FC24E72?sequence=1 (accessed on 30 November 2018).

13. Walsh, D.; Bendel, N.; Jones, R.; Hanlon, P. It's not 'just deprivation': Why do equally deprived UK cities experience different health outcomes? Public Health 2010, 124, 487-495. [CrossRef] [PubMed]

14. Marmot, M.; Bell, R. Fair society, healthy lives. Public Health 2012, 126, S4-S10. [CrossRef] [PubMed]

15. Scarborough, P.; Bhatnagar, P.; Wickramasinghe, K.K.; Allender, S.; Foster, C.; Rayner, M. The economic burden of ill health due to diet, physical inactivity, smoking, alcohol and obesity in the UK: An update to 2006-07 NHS costs. J. Public Health 2011, 33, 527-535. [CrossRef] [PubMed]

16. Naylor, C.; Parsonage, M.; McDaid, D.; Knapp, M.; Fossey, M.; Galea, A. Long-Term Conditions and Mental Health: The Cost of Co-Morbidities; The Kings Fund and Centre for Mental Health Report; The Kings Fund: London, UK, 2011.

17. NHS. Health Survey for England: Weight. In NHS Digital; 2016. Available online: http://healthsurvey.hscic. gov.uk/data-visualisation/data-visualisation/explore-the-trends/weight.aspx (accessed on 30 November 2018).

18. Al-Goblan, A.S.; Al-Alfi, M.A.; Khan, M.Z. Mechanism linking diabetes mellitus and obesity. Diabetes Metab. Syndr. Obes. Targets Ther. 2014, 7, 587-591. [CrossRef] [PubMed]

19. Riley, L.; Guthold, R.; Cowan, M.; Savin, S.; Bhatti, L.; Armstrong, T.; Bonita, R. The World Health Organization STEPwise approach to noncommunicable disease risk-factor surveillance: Methods, challenges, and opportunities. Am. J. Public Ealth 2016, 106, 74-78. [CrossRef] [PubMed]

20. Bridges, A.J.; Andrews, A.R., III; Villalobos, B.T.; Pastrana, F.A.; Cavell, T.A.; Gomez, D. Does integrated behavioral health care reduce mental health disparities for Latinos? Initial findings. J. Lat. Psychol. 2014, 2, 37-53. [CrossRef] [PubMed]

21. McManus, S.; Bebbington, P.; Jenkins, R.; Brugha, T. Mental Health and Wellbeing in England: Adult Psychiatric Morbidity Survey 2014: A Survey Carried Out for NHS Digital by NatCen Social Research and the Department of Health Sciences, University of Leicester. NHS Digital, 29 September 2016.

22. Patel, V.; Chatterji, S. Integrating mental health in care for noncommunicable diseases: An imperative for person-centered care. Health Aff. 2015, 34, 1498-1505. [CrossRef]

23. Varghese, $\mathrm{C}$. Reducing premature mortality from non-communicable diseases, including for people with severe mental disorders. World Psychiatry 2017, 16, 45-47. [CrossRef]

24. Allen, L.N.; Feigl, A.B. What's in a name? A call to reframe non-communicable diseases. Lancet Glob. Health 2017, 5, e129-e130. [CrossRef]

25. Nethan, S.; Sinha, D.; Mehrotra, R. Non Communicable Disease Risk Factors and their Trends in India. Asian Pac. J. Cancer Prev. 2017, 18, 2005-2010.

26. Soliveres, S.; Van Der Plas, F.; Manning, P.; Prati, D.; Gossner, M.M.; Renner, S.C.; Alt, F.; Arndt, H.; Baumgartner, V.; Binkenstein, J.; et al. Biodiversity at multiple trophic levels is needed for ecosystem multifunctionality. Nature 2016, 536, 456-459. [CrossRef] [PubMed] 
27. Pienkowski, T.; Dickens, B.L.; Sun, H.; Carrasco, L.R. Empirical evidence of the public health benefits of tropical forest conservation in Cambodia: A generalised linear mixed-effects model analysis. Lancet Planet. Health 2017, 1, e180-e187. [CrossRef]

28. Oliveira Hagen, E.; Hagen, O.; Ibáñez-Álamo, J.D.; Petchey, O.L.; Evans, K.L. Impacts of urban areas and their characteristics on avian functional diversity. Front. Ecol. Evolut. 2017, 5, 84. [CrossRef]

29. Allentoft, M.E.; O’Brien, J. Global amphibian declines, loss of genetic diversity and fitness: A review. Diversity 2010, 2, 47-71. [CrossRef]

30. Pinsky, M.L.; Palumbi, S.R. Meta-analysis reveals lower genetic diversity in overfished populations. Mol. Ecol. 2014, 23, 29-39. [CrossRef]

31. Ceulemans, T.; Stevens, C.J.; Duchateau, L.; Jacquemyn, H.; Gowing, D.J.; Merckx, R.; Wallace, H.; Van Rooijen, N.; Goethem, T.; Bobbink, R.; et al. Soil phosphorus constrains biodiversity across European grasslands. Glob. Chang. Biol. 2014, 20, 3814-3822. [CrossRef]

32. Prescott, S.L.; Logan, A.C. Larger than life: Injecting hope into the planetary health paradigm. Challenges 2018, 9, 13. [CrossRef]

33. Myers, S.S. Planetary health: Protecting human health on a rapidly changing planet. Lancet 2017, 390, 2860-2868. [CrossRef]

34. Canavan, C.R.; Noor, R.A.; Golden, C.D.; Juma, C.; Fawzi, W. Sustainable food systems for optimal planetary health. Trans. R. Soc. Trop. Med. Hyg. 2017, 111, 238-240. [CrossRef]

35. Schwartz, R.M.; Liu, B.; Lieberman-Cribbin, W.; Taioli, E. Displacement and mental health after natural disasters. Lancet Planet. Health 2017, 1, e314. [CrossRef]

36. Borrell-Carrió, F.; Suchman, A.L.; Epstein, R.M. The biopsychosocial model 25 years later: Principles, practice, and scientific inquiry. Ann. Fam. Med. 2004, 2, 576-582. [CrossRef]

37. Prescott, S.L.; Logan, A.C. Down to earth: Planetary health and biophilosophy in the symbiocene epoch. Challenges 2017, 8, 19. [CrossRef]

38. Albrecht, G. Ecopsychology in the Symbiocene. Ecopsychology 2014, 6, 58-59. [CrossRef]

39. Huff, C. The growth of holistic health. Philadelphia Inquirer, 3 November 1977; 52.

40. Salk, J.E. Biology in the future. Perspect. Biol. Med. 1962, 5, 423-431. [CrossRef] [PubMed]

41. Gehlert, S.; Murray, A.; Sohmer, D.; McClintock, M.; Conzen, S.; Olopade, O. The importance of transdisciplinary collaborations for understanding and resolving health disparities. Soc. Work Public Health 2010, 25, 408-422. [CrossRef] [PubMed]

42. Nyatanyi, T.; Wilkes, M.; McDermott, H.; Nzietchueng, S.; Gafarasi, I.; Mudakikwa, A.; Kinani, J.F.; Rukelibuga, J.; Omolo, J.; Mupfasoni, D.; et al. Implementing One Health as an integrated approach to health in Rwanda. BMJ Glob. Health 2017, 2, e000121. [CrossRef]

43. Kesebir, S.; Kesebir, P. A growing disconnection from nature is evident in cultural products. Perspect. Psychol. Sci. 2017, 12, 258-269. [CrossRef] [PubMed]

44. Lederbogen, F.; Kirsch, P.; Haddad, L.; Streit, F.; Tost, H.; Schuch, P.; Wüst, S.; Pruessner, J.C.; Rietschel, M.; Deuschle, M.; et al. City living and urban upbringing affect neural social stress processing in humans. Nature 2011, 474, 498-501. [CrossRef] [PubMed]

45. Cox, D.T.; Shanahan, D.F.; Hudson, H.L.; Plummer, K.E.; Siriwardena, G.M.; Fuller, R.A.; Anderson, K.; Hancock, S.; Gaston, K.J. Doses of neighborhood nature: The benefits for mental health of living with nature. BioScience 2017, 67, 147-155. [CrossRef]

46. Bertram, C.; Rehdanz, K. The role of urban green space for human well-being. Ecol. Econ. 2015, 120, $139-152$. [CrossRef]

47. Soga, M.; Gaston, K.J. Extinction of experience: The loss of human-nature interactions. Front. Ecol. Environ. 2016, 14, 94-101. [CrossRef]

48. Kuenzig, M.E.; Barnabe, C.; Seow, C.H.; Eksteen, B.; Negron, M.E.; Rezaie, A.; Panaccione, R.; Benchimol, E.I.; Sadatsafavi, M.; Aviña-Zubieta, J.A.; et al. Asthma is associated with subsequent development of inflammatory bowel disease: A population-based case-control study. Clin. Gastroenterol. Hepatol. 2017, 15, 1405-1412. [CrossRef] [PubMed]

49. Earl, C.S.; An, S.Q.; Ryan, R.P. The changing face of asthma and its relation with microbes. Trends Microbiol. 2015, 23, 408-418. [CrossRef] [PubMed]

50. Robinson, J.; Mills, J.; Breed, M. Walking Ecosystems in Microbiome-Inspired Green Infrastructure: An Ecological Perspective on Enhancing Personal and Planetary Health. Challenges 2018, 9, 40. [CrossRef] 
51. Robinson, J.M.; Jorgensen, A. Rekindling Old Friendships in New Landscapes: The Environment-Microbiome-Health Axis in the Realms of Landscape Research. People Nat. 2018, under review.

52. Rook, G.A. Regulation of the immune system by biodiversity from the natural environment: An ecosystem service essential to health. Proc. Natl. Acad. Sci. USA 2013, 110, 18360-18367. [CrossRef] [PubMed]

53. Wen, L.M.; Kite, J.; Merom, D.; Rissel, C. Time spent playing outdoors after school and its relationship with independent mobility: A cross-sectional survey of children aged 10-12 years in Sydney, Australia. Int. J. Behav. Nutr. Phys. Act. 2009, 6, 15. [CrossRef] [PubMed]

54. Rosiek, A.; Maciejewska, N.F.; Leksowski, K.; Rosiek-Kryszewska, A.; Leksowski, Ł. Effect of television on obesity and excess of weight and consequences of health. Int. J. Environ. Res. Public Health 2015, 12, 9408-9426. [CrossRef]

55. Bekoff, M.; Bexell, S.M. Ignoring nature: Why we do it, the dire consequences, and the need for a paradigm shift to save animals, habitats, and ourselves. Hum. Ecol. Rev. 2010, 17, 70-74.

56. Pérez, C.G.; Soutelo, S.G.; Mosqueira, M.M.; Soto, J.L. Spa techniques and technologies: From the past to the present. Sustain. Water Resour. Manag. 2017. [CrossRef]

57. van Tubergen, A.; van der Linden, S. A brief history of spa therapy. Ann. Rheum. Dis. 2002, 61, $273-275$. [CrossRef] [PubMed]

58. Maretzki, T.W. The Kur in West Germany as an interface between naturopathic and allopathic ideologies. Soc. Sci. Med. 1987, 24, 1061-1068. [CrossRef]

59. Antonelli, M.; Donelli, D. Effects of balneotherapy and spa therapy on levels of cortisol as a stress biomarker: A systematic review. Int. J. Biometeorol. 2018, 62, 913-924. [CrossRef] [PubMed]

60. Jepson, R.; Robertson, R.; Cameron, H. Green Prescription Schemes: Mapping and Current Practice; NHS Health Scotland: Edinburgh, UK, 2010.

61. Patel, A.; Schofield, G.M.; Kolt, G.S.; Keogh, J.W. General practitioners' views and experiences of counselling for physical activity through the New Zealand Green Prescription program. BMC Fam. Pract. 2011, 12, 119. [CrossRef] [PubMed]

62. Kolt, G.S.; Schofield, G.M.; Kerse, N.; Garrett, N.; Schluter, P.J.; Ashton, T.; Patel, A. The Healthy Steps Study: A randomized controlled trial of a pedometer-based Green Prescription for older adults. Trial protocol. BMC Public Health 2009, 9, 404. [CrossRef]

63. Victoria State Government. Gardening-People with Disabilities. 2018. Available online: https: //www.betterhealth.vic.gov.au/health/healthyliving/gardening-people-with-disabilities (accessed on 30 November 2018).

64. Poulsen, D.; Stigsdotter, U.; Davidsen, A. “That Guy, Is He Really Sick at All?” An Analysis of How Veterans with PTSD Experience Nature-Based Therapy. InHealthcare 2018, 6, 64. [CrossRef] [PubMed]

65. Millar, S.L.; Donnelly, M. Promoting mental wellbeing: Developing a theoretically and empirically sound complex intervention. J. Public Health 2013, 36, 275-284. [CrossRef] [PubMed]

66. Seymour, V.; King, M.; Antonaci, R. Understanding the impact of volunteering on pro-environmental behavioural change. Volunt. Sect. Rev. 2018, 9, 73-88. [CrossRef]

67. Annis, G.M.; Pearsall, D.R.; Kahl, K.J.; Washburn, E.L.; May, C.A.; Taylor, R.F.; Cole, J.B.; Ewert, D.N.; Game, E.T.; Doran, P.J. Designing coastal conservation to deliver ecosystem and human well-being benefits. PLoS ONE 2017, 12, e0172458. [CrossRef] [PubMed]

68. Flies, E.J.; Skelly, C.; Lovell, R.; Breed, M.F.; Phillips, D.; Weinstein, P. Cities, biodiversity and health: We need healthy urban microbiome initiatives. Cities Health 2018. [CrossRef]

69. Mills, J.G.; Weinstein, P.; Gellie, N.J.; Weyrich, L.S.; Lowe, A.J.; Breed, M.F. Urban habitat restoration provides a human health benefit through microbiome rewilding: The Microbiome Rewilding Hypothesis. Restor. Ecol. 2017, 25, 866-872. [CrossRef]

70. Vardakoulias, O. The Economic Benefits of Ecominds: A Case Study Approach. MIND. July 2013. Available online: https:/ / www.mind.org.uk/media/338566/The-Economic-Benefits-of-Ecominds-report. pdf (accessed on 15 January 2019).

71. Kimberlee, R. Gloucestershire clinical commissioning group's social prescribing service: Evaluation report. 2016. Available online: http:/ / eprints.uwe.ac.uk/30293/ (accessed on 15 January 2019). 
72. Dayson, C.; Bashir, N.; Bennett, E. The Rotherham Social Prescribing Service for People with Long-term Health Conditions. Annual Report; Sheffield Hallam University: Sheffield, UK, 2016; Available online: http:/ / shura. shu.ac.uk/17296/1/rotherham-social-prescribing-service-annual-report.pdf (accessed on 1 December 2018).

73. Seltenrich, N. Just what the doctor ordered: Using parks to improve children's health. Environ. Health Perspect. 2015, 123, A254-A529. [CrossRef] [PubMed]

74. Maier, J.; Jette, S. Promoting nature-based activity for people with mental illness through the US “Exercise Is Medicine" initiative. Am. J. Public Health 2016, 106, 796-799. [CrossRef] [PubMed]

75. Swinburn, B.A.; Walter, L.G.; Arroll, B.; Tilyard, M.W.; Russell, D.G. Green prescriptions: Attitudes and perceptions of general practitioners towards prescribing exercise. Br. J. Gen Pr. 1997, 47, 567-569.

76. Gribben, B.; Goodyear-Smith, F.; Grobbelaar, M.; O'Neill, D.; Walker, S. The early experience of general practitioners using Green Prescription. N. Z. Med. J. 2000, 113, 372-373. [PubMed]

77. Lovell, R.; Depledge, M.; Maxwell, S. Health and the Natural Environment: A Review of Evidence, Policy, Practice and Opportunities for the Future. 2018. Available online: https:/ / beyondgreenspace.net/2018/09/ 07/defra_health_review / (accessed on 30 November 2018).

78. Bell, S.L.; Leyshon, C.; Foley, R.; Kearns, R.A. The "healthy dose" of nature: A cautionary tale. Geogr. Compass. 2018, e12415. [CrossRef]

79. Husk, K.; Lovell, R.; Garside, R. Prescribing gardening and conservation activities for health and wellbeing in older people. Maturitas 2018, 110, A1-A2. [CrossRef]

80. Allen, R.W.; Barn, P.K.; Lanphear, B.P. Randomized controlled trials in environmental health research: Unethical or underutilized? PLoS Med. 2015, 12, e1001775. [CrossRef]

(C) 2019 by the authors. Licensee MDPI, Basel, Switzerland. This article is an open access article distributed under the terms and conditions of the Creative Commons Attribution (CC BY) license (http://creativecommons.org/licenses/by/4.0/). 